\title{
Psychological support for a community paediatric nursing team
}

\author{
Gill Salmon and Anne Marie Connor
}

\begin{abstract}
We describe how a support group was set up and run over a ten-month period for members of a community paediatilc nursing team. The views of the trainee who facilltated the group and of the nurse manager are offered.
\end{abstract}

In recent years there have been considerable changes within the National Health Service which have resulted in increased responsibility for many practitioners. These changes have included the introduction of the internal market, changes in skill $\mathrm{mix}$, and for nurses, clinical regrading and the implementation of Project 2000 with its resulting implications for staffing levels. Concurrently, despite the strong endorsement of various Governmental reports (Platt, 1959; Court, 1976; Audit Commission, 1986) and a realisation of the detrimental effects of hospitalisation upon children, the development of community nursing services specifically for children has been slow and problematic and has not paralleled the increasing number of sick children with complex medical conditions and needs. As a result, many community paediatric nurses, like other health care professionals, are experiencing much higher levels of work-related stress.

A major rationale for offering staff support is the need for quality patient care. It has been shown that an increase in perceived work support among nurses is associated with improved work performance, as well as with increased job satisfaction (Parkes, 1982). A support group can be a forum for staff to identify behaviours that may be contributing to problem situations, such as ineffective communication patterns or unrealistic expectations of self, team members or administration (Guillory \& Riggin, 1991). Expression and sharing of feelings, and open communication can also lead to the resolution of conflicts within the team (Weiner \& Caldwell, 1983-1984; Jenkins \& Stevenson, 1991).

In this paper we describe how a support group was set up and run over a 10-month period for members of a community paediatric nursing team. The views, both of the trainee who facilitated the group (GS) and of the nurse manager (AC), are offered.

\section{The community paediatric nursing team}

The team comprised a clinical nurse specialist (AC) who was also the team manager, three parttime sick children's nurses and a play therapist. Team members supported children, many of whom suffered from chronic and sometimes terminal disease, and their families at home, both on a technical and a psychological level. There was often some overlap of cases, with more than one team member having involvement with any one family.

\section{The facilitator's view}

While working as a senior registrar in a Child and Family Psychiatric Service (CFPS), I was asked by two members of the team to provide regular psychological support in relation to their work with children with leukaemia and their families. It soon became apparent that other team members were keen to join them. I thus agreed to meet with the team once a month for one hour and suggested that the agenda be broadened to anything that was work-related.

It seemed important to meet in a place away from the community team base so that team members could separate themselves from their other work commitments and have time and space to reflect, free from interruptions. For that reason we met at the CFPS, a short distance from the base hospital. Because of leave, and so on. attendance each month varied from two to four team members.

During our fourth meeting, time was set aside for feedback. It was subsequently decided to extend the duration of meetings from one hour to one and a quarter hours and that at the start of each meeting an agenda would be set.

During the course of the group, several common themes emerged. These included: 
feelings of inadequacy, of not 'doing enough' or being 'good enough'; parental denial of illness; the importance of establishing firm boundaries around what the team could and couldn't offer; other boundary issues, for example visiting families out of hours or at weekends or babysitting, which made it difficult for staff to maintain a professional distance; difficulties terminating contact with families; setting limits with parents who acted unreasonably or who were, at times, extremely hostile or unpleasant; and dealing with bereavement issues. Exploration of these conflicts seemed important in helping team members become more tolerant of patients and parents whom they experienced as difficult.

Occasionally, issues relating to the team or other staff were explored such as negotiating individual roles with families/patients where more than one team member was involved, hierarchy within the staff team, and whether or not other professionals should be invited to attend the group from time to time (e.g. nursing students or health visitors) and the resultant effect of these latter two issues on group dynamics.

As the facilitator of the group, one issue I particularly struggled with was how to remain detached enough to be objective in the face of being welcomed with 'open arms' by the team members. Perhaps this conflict reflected the difficulties the team faced in gauging their relationships with families and the importance of maintaining a professional distance.

It was notable that two months before I was due to go on maternity leave, a whole session revolved around issues of loss and bereavements that the team expected to have to deal with after I had gone. I had a sense of the team feeling that they would be left unsupported at the very time they needed it most. It was following this session that I arranged for one of my colleagues to facilitate the group in my absence, a reflection perhaps of the team's difficulty in withdrawing support from families once established.

\section{The nurse manager's view}

When I was initially approached by a colleague about the possibility of the team receiving regular psychological support in relation to our work as community paediatric nurses, I was sceptical about the prospect. This was in spite of my being very much in favour of the general concept of staff support.

The reality was, however, that I questioned if I had enough spare time available to attend regular support sessions. I had difficulty enough fulfilling my own work commitments both as a clinician and manager. I wondered also how I would justify the 'time out' required to my own nurse manager. Despite my initial doubts, however, I was encouraged by the enthusiasm of my colleagues and so with a slight feeling of trepidation attended the first group.

Looking back, I remember vividly the first session I attended. I think that one of my biggest anxieties beforehand was the assumption that I had to have a problem to bring to the group. I just couldn't think of anything. That very morning. however, I had been involved with a family about whom I had been extremely concerned. As a result of that encounter I felt that my professional boundaries were being threatened and that the parents' expectations of what I could provide were unrealistic. I casually mentioned the interaction and was soon pouring my heart out'. Interestingly. I found that my feelings were shared by other team members.

Initial reservations about the group were quickly replaced by great enthusiasm. Perhaps the fact that I initially could not think of anything to discuss reflected how I had previously coped with problem situations at work. While, as a team, I felt we shared anxieties and discussed issues which were of concern with families, the lack of access to appropriate psychological support meant that underlying issues inherent to the situation were not addressed and remained unresolved. A large amount of group time was spent discussing the setting of boundaries with families. This paid dividends, since many strategies which were suggested and subsequently tried out were found to be effective.

It was also interesting observing the changes which occurred within our team. When problem situations arose with families we found ourselves being more objective and even if a solution was not immediately apparent, panic did not ensue. Instead we put the problem 'on hold' until the next session. In this way I felt that we were less reactive in difficult situations, and this reduced anxiety levels considerably.

An important factor in the success of the group, for me, was that it was held away from our place of work. For any individual considering setting up a support group, the venue may not seem to be a principal consideration. The importance of 'getting away' should not be underestimated, however. All of my colleagues commented on how beneficial it was being able to discuss feelings, fears, anxieties and expectations on neutral territory'. The lack of apparent hierarchy within the group also seemed important and all members were respected for their contributions.

\section{Conclusion}

As individuals, the team members seemed to greatly value the group and spoke positively to other professonals of the benefits they felt came 
as a result of attending. Important factors in the success of the group appeared to be that the request for support had come from the team members, the neutral location, and the review after several months which helped to tailor the group to the member's evolving needs.

In the resource-driven climate of the NHS, staff support and supervision is often an afterthought. However, the benefits gained can be considerable and may enhance the quality of care on offer. Clearly, if continued quality care is to be delivered to patients then the needs of practitioners must be given more consideration.

\section{Acknowledgements}

We would like to thank Dr Renuka Nagraj for her support, encouragement and supervision both in setting up the group and in writing this article.

\section{References}

Audrr Commission (1986) Making a Reality of Community Care. London: HMSO.
CourT, S. D. M. (1976) Fut for the Future. Report of the Committee of Child Health Services. London: HMSO.

GumLORY, B. A. \& RiGGiN, O. Z. (1991) Developing a nursing staff support group model. Clinical Nurse Spectalist. 8 . 170-173.

JENKINS, E. \& STEVENSON, I. (1991) A strategy for managing change and stress: developing staff support groups. Professional Nurse, July, 579-581.

PARKES, K. (1982) Occupational stress among student nurses: a natural experiment. Journal of Applied Psychology, 67, 784-796.

PLATT, H. (1959) The Welfare of Children in Hospital. Report of the committee of child health services council. London: HMSO.

WeINER, M. \& CALDWELl. T. (1983-84) The process and impact of an ICU nurse support group. International Journal of Psychiatry in Medicine, 13, 47-55.

*Gill Salmon, Senior Registrar in Child and Adolescent Psychiatry. The Park Hospital for Children, Old Road, Headington, Oxford OX3 7LQ; and Ann Marie Connor, formerly Clinical Nurse Specialist, Community Paediatric Nursing Team, Stoke Mandeville Hospital, Mandeville Road, Aylesbury, Bucks HP21 8AL

*Correspondence

\section{New from Gaskell}

\section{Safeguards for Young Minds}

\section{Young People and Protective Legislation}

\section{Richard White, Richard Williams, Anthony Harbour and William Bingley}

This co-publication with the NHS Health Advisory Service is concerned with aspects of the law as it applies to the welfare and protection of minors, and the management of children and adolescents in mental health services. It includes a complete update of the Concise Guide to the Children Act 1989, with a concise summary of the provisions of the Children Act. Particular issues relating to the use of the Mental Health Act 1983 with younger people and recent developments wrought by case law are also covered. Price £10.00, 84pp., 1996, ISBN $090224194 \mathrm{X}$

Available from good bookshops and from the Publications Department, Royal College of Psychiatrists, 17 Belgrave Square, London SWIX 8PG. Credit card orders can taken over the telephone (+44(0) I 7 I-235 235I, extension 146)

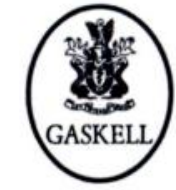

